\title{
Deformation twinning in a nanocrystalline hep Mg alloy
}

\author{
X.L. Wu, ${ }^{a}$ K.M. Youssef, ${ }^{\text {b C.C. Koch, }}{ }^{\mathrm{b}}$ S.N. Mathaudhu, ${ }^{\mathrm{c}}$ L.J. Kecskés ${ }^{\mathrm{c}}$ and Y.T. Zhu ${ }^{\mathrm{b}, *}$ \\ ${ }^{a}$ State Key Laboratory of Nonlinear Mechanics, Institute of Mechanics, Chinese Academy of Sciences, Beijing 100190, China \\ ${ }^{\mathrm{b}}$ Department of Materials Science \& Engineering, North Carolina State University, Raleigh, NC 27695-7919, USA \\ ${ }^{c}$ U.S. Army Research Laboratory, Aberdeen Proving Ground, MD 21005, USA
}

Received 19 March 2010; revised 14 October 2010; accepted 18 October 2010

Available online 30 October 2010

\begin{abstract}
Nanocrystalline (nc) hexagonal close-packed (hcp) metals are rarely observed to deform by twinning, which is contrary to facecentered cubic metals. Here we report that, after alloying $\mathrm{Mg}$ with 10 at.\% $\mathrm{Ti}$, deformation twins are observed in an nc $\mathrm{Mg}-\mathrm{Ti}$ alloy processed by mechanical attrition. The formation of deformation twins is attributed to the alloying effect, which may change the energy path for twinning. These results point to a promising approach to design nc hcp alloys for superior mechanical properties. (C) 2010 Acta Materialia Inc. Published by Elsevier Ltd. All rights reserved.
\end{abstract}

Keywords: Twinning; Nanocrystalline; hcp; Mg; Alloying

Nanocrystalline (nc) materials usually have high strength, but disappointingly low ductility [1]. Early attempts to increase the ductility often resulted in decrease in strength [2,3], although in some cases both high strength and good ductility are observed [4]. Twins in nc face-centered cubic (fcc) materials have been reported to increase both the strength and the ductility by accumulating dislocations at the twin boundaries [5]. Fortunately, fcc materials have been found to deform by twinning easily in their nc state $[6,7]$. This makes deformation twinning one of the most promising strategies for simultaneously increasing the strength and ductility of nc fcc metals and alloys [8-11]. However, this important strategy for improving the strength and ductility has so far not been available to nc hexagonal closepacked (hcp) metals and alloys because they rarely deform by twinning [12].

The twinning behavior of hep materials is very different from that of fcc metals. For fcc metals, with decreasing grain size it becomes more difficult to deform by twinning in the coarse-grain size range [13], but twinning becomes easier once the grain size is smaller than $100 \mathrm{~nm}$ [6], although twinning may become difficult again when the grain size is too small (inverse grain size effect) [14]. In contrast, coarse-grained hcp metals usually need twinning to accommodate plastic deformation in addition to dislocation slip due to their lack of sufficient slip systems. However, twinning is rarely observed

\footnotetext{
* Corresponding author. Tel.: +1 9195130559 ; e-mail: ytzhu@ncsu.edu
}

in nc hcp metals and alloys, with the exception of $\mathrm{nc} \mathrm{Zr}$ processed by surface mechanical attrition [15]. The reason for the observed grain size effect on twinning in hcp materials is not clear. It would be scientifically and technically important to activate deformation twinning in nc hep metals.

It is the objective of this investigation to activate deformation twinning in hep $\mathrm{Mg}$ by adding $\mathrm{Ti}$ as the alloying element. Alloying will change the energy path for twinning, i.e. the general planar fault energy (GPFE) curves, and this will affect propensity for twinning [16]. We choose $\mathrm{Mg}$ as a model material in this study because it has the lowest density among structural metals except for $\mathrm{Be}$. $\mathrm{Ti}$ is chosen as the alloying element because it has a high solubility in $\mathrm{Mg}$ when processed by ball milling $[17,18]$.

Nanocrystalline $\mathrm{Mg}-10$ at.\% $\mathrm{Ti}$ samples were prepared by ball milling in a SPEX 8000 mill, using a steel vial and balls. Starting materials were elemental powders of $\mathrm{Mg}(99.9 \%)$ and $\mathrm{Ti}(99.5 \%)$. X-ray analysis reveals the Bragg peaks corresponding to the hcp $\mathrm{Mg}$ phase after milling for $24 \mathrm{~h}$, indicating that no new phases formed and the Ti formed a solid solution with $\mathrm{Mg}$ (see Fig. 1a). Note the shift in the Mg alloy peaks to higher $2 \theta$ angles, indicative of a contraction of the lattice parameter. This is important because only when Ti forms a solid solution can it lower the stacking fault energy. For simplicity, the $\mathrm{Mg}-10$ at.\% Ti alloy is hereafter referred to as the $\mathrm{Mg}-\mathrm{Ti}$ alloy. Shown in Figure $1 \mathrm{~b}$ is the statistical distribution of grain sizes with an average grain size of $33 \mathrm{~nm}$. 

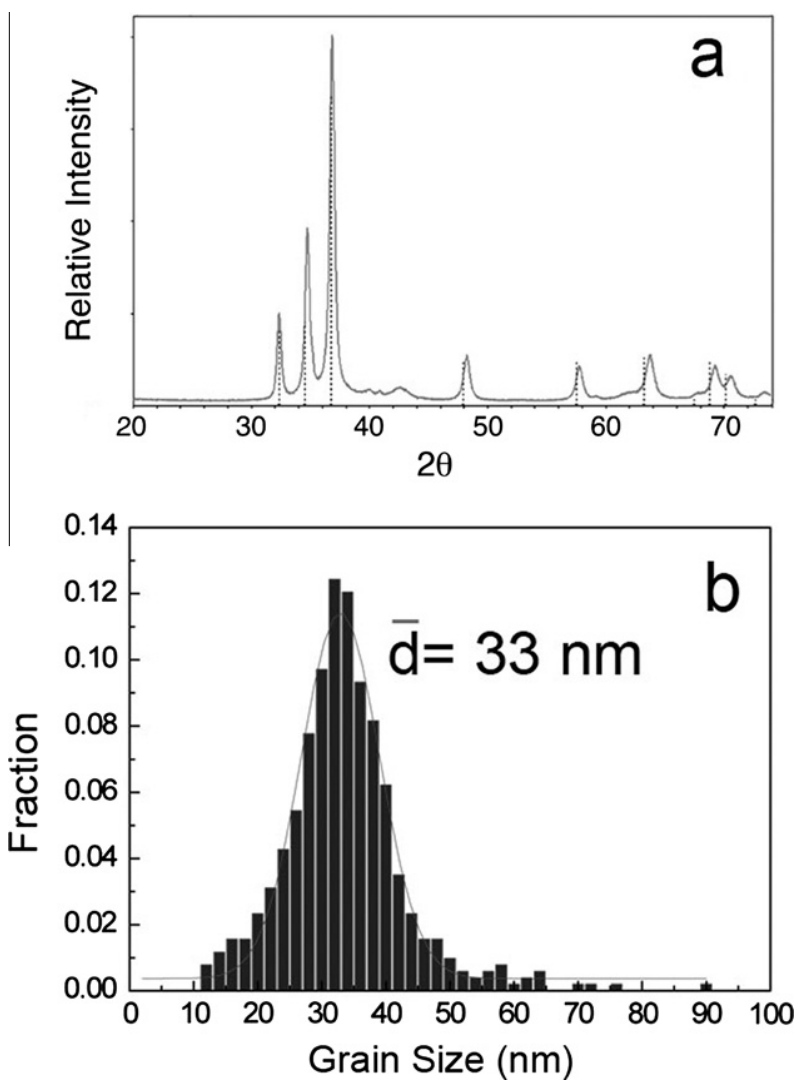

Figure 1. (a) X-ray diffraction pattern indicating a single hep $\mathrm{Mg}$ phase. (b) Statistical distribution of grain sizes in the as-processed nc $\mathrm{Mg}-\mathrm{Ti}$ alloy, measured from over 500 grains in transmission electron microscopy micrographs. The average grain size is $33 \mathrm{~nm}$.

Figure 2 shows high-resolution electron microscopy (HREM) images of two deformation twins in the as-processed nc Mg-Ti alloy. The images are viewed from a $\left[\begin{array}{llll}1 & 1 & 2 & 3\end{array}\right]$ zone axis. Coherent twin boundaries and mirror images of atomic arrangements are clearly shown, verifying that they are indeed twins. Importantly, a twoatomic-layer step on the coherent twin boundary is shown in both Figure $2 \mathrm{a}$ and $\mathrm{b}$ (marked by 2 ). In addition, there also exist two one-layer steps on the coherent twin boundary in Figure $2 \mathrm{a}$ and one one-layer step in Figure $2 b$ (marked by 1 ). The most common twinning system observed in hep $\mathrm{Mg}$ is $\{10 \overline{1} 2\}\langle 10 \overline{1} 1\rangle[19,20]$. The $\{10 \overline{1} 1\}\langle 10 \overline{1} \overline{2}\rangle$ deformation twins observed in this study are consistent with the twinning mode observed in MD simulation of $\mathrm{Mg}$ under compression [19]. Interestingly, this twinning system was also observed in hep $\mathrm{Ti}$ and $\mathrm{Zr}$ processed by severe plastic deformation under pressure, although the twinning only happened in large grains $[21,22]$. MD simulation predicted that $\{10 \overline{1} 1\}$ $\langle 10 \overline{1} \overline{2}\rangle$ deformation twins grow by the slip of a zonal twinning dislocation, $1 / 2 \bullet 1 / 2\langle 10 \overline{1} \overline{2}\rangle$, on the coherent $(10 \overline{1} 1)$ twin boundary, followed by atomic shuffling. This zonal dislocation involves two (10 $\overline{1} 1)$ planes, forming a two-layer step on the twin boundary. Such two-layer steps are indeed observed in Figure 2, which clearly verifies this twinning mechanism predicted by the MD simulation. The MD simulation also predicted that the one-layer steps are immobile and that the four-layer steps are unstable and can spontaneously

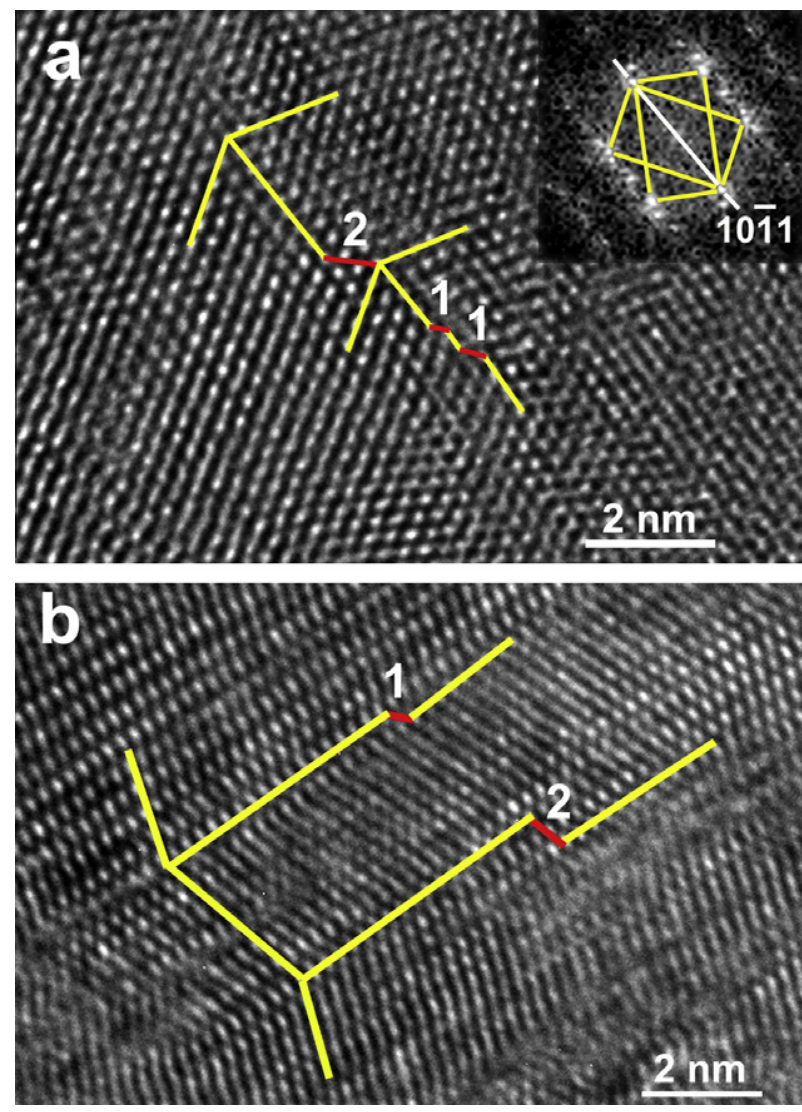

Figure 2. (a) HREM micrograph showing a deformation twin in the nc Mg-Ti alloy, viewed along a [1 $1 \overline{2} 3]$ zone axis. The twin system is $\{10 \overline{1} 1\}\langle 10 \overline{1} \overline{2}\rangle$. A two-atomic-layer step and two one-layer steps are on the twin boundary. (b) HREM micrograph showing another deformation twin with a two-layer step on the lower twin boundary and a one-layer step on the upper twin boundary.

dissociate into two two-layer steps [19]. The one-layer steps are experimentally observed in Figure 2, while no four-layer steps have been observed in our samples. Interestingly, Figure 2a shows two one-layer steps next to each other, which could merge to form a two-layer step, i.e. a zonal twinning dislocation. Over 50 grains in nc Mg-Ti alloy were observed from [ $111 \overline{2} 3]$ zone axis, all of which contain deformation twins. It has been reported that ball-milled nanocrystalline $\mathrm{Mg}$ with grain sizes similar to the our nc Mg-Ti alloy do not deform by twinning $[23,24]$.

Figure 3 shows several $\langle\overline{1} 123\rangle$ dislocations in the nc Mg-Ti alloy (marked by $\mathrm{T}$ ), lying on the $\{10 \overline{1} 1\}$ planes. The $\{1011\}\langle 1123\rangle$ slip system can produce strain in both the $a$-axis and the $c$-axis directions. This is very important because the slip system of coarse-grained

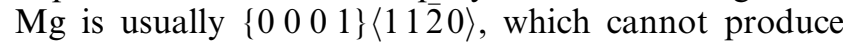
strain in the $c$-axis direction. The activation of the $\{10 \overline{1} 1\}\langle\overline{1} \overline{1} 23\rangle$ slip system should help with the plastic deformation of the nc Mg-Ti alloy. This also indicates that the nc hcp Mg-Ti alloy deforms via slip systems that are normally not active in coarse-grained $\mathrm{Mg}$, a phenomenon similar to that observed in nc fcc materials.

Although X-ray analysis verified that $\mathrm{Ti}$ solute completely dissolved into the $\mathrm{Mg}$ matrix to form a hcp solid solution (Fig. 1a), there remains the questions of 


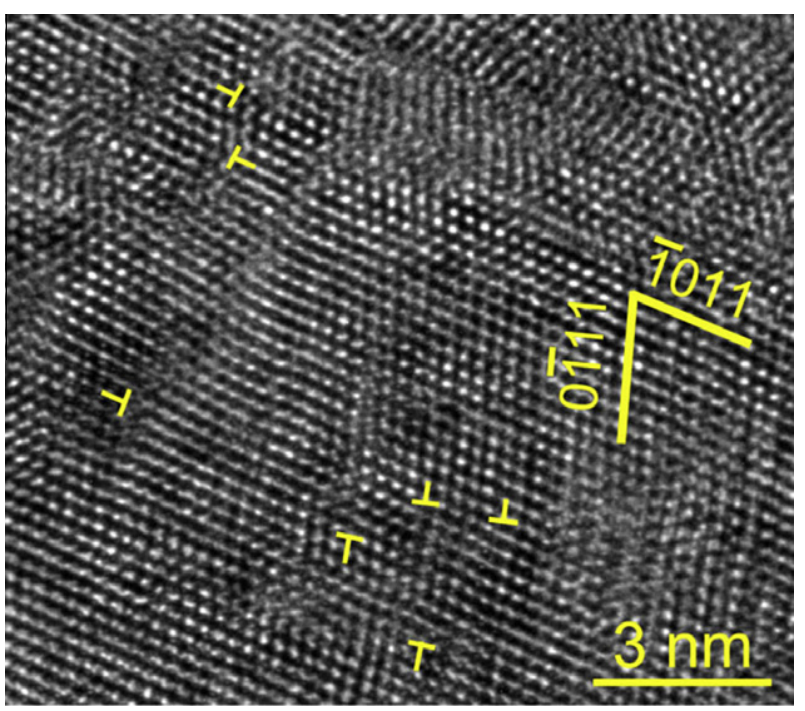

Figure 3. HREM image showing $\langle\overline{1} \overline{1} 23\rangle$ dislocations on $\{10 \overline{1} 1\}$ planes. The zone axis is $[\overline{1} 2 \overline{1} 3]$.

whether the Ti solute is uniformly distributed in the $\mathrm{Mg}$ matrix and if there is a grain size effect. To answer these questions, we performed energy-dispersive X-ray (EDX) analysis on grains of the $\mathrm{nc} \mathrm{Mg}-\mathrm{Ti}$ alloy. Shown in Figure $4 \mathrm{a}$ are two grains with sizes of 35 and $50 \mathrm{~nm}$, respectively. Figure $4 \mathrm{~b}$ shows that the Ti atoms are distributed uniformly in the small grain. However, in the large grain, Ti has a higher concentration in the area near the grain boundary than in the area near the grain cen-
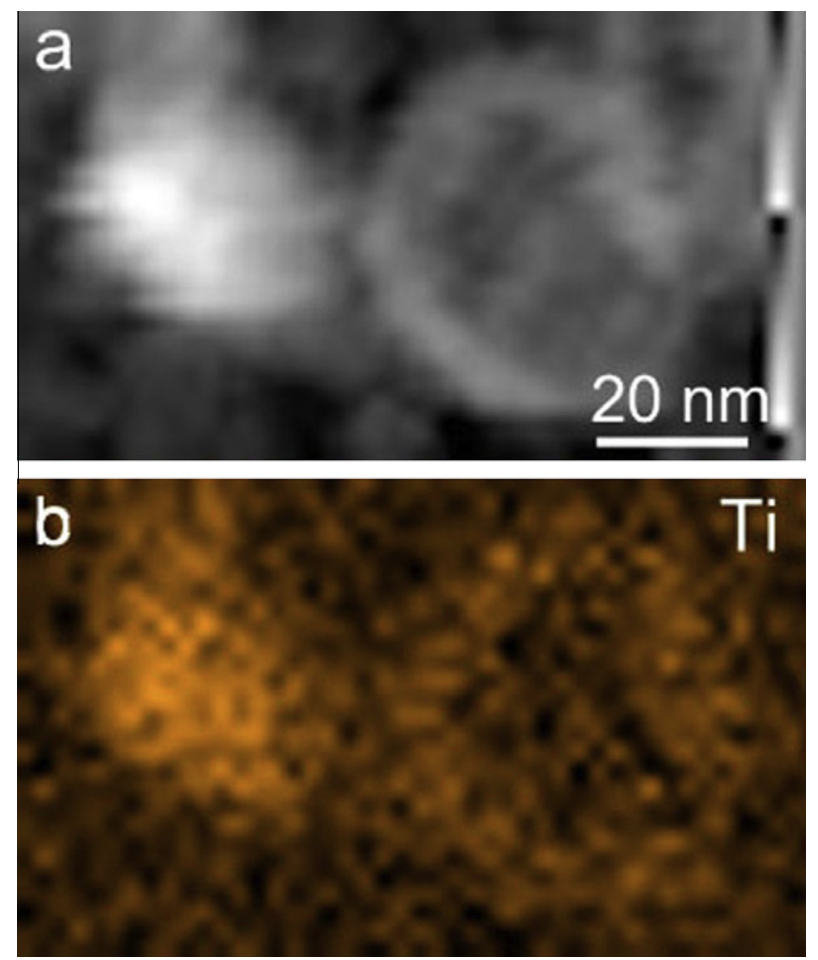

Figure 4. (a) EDX images of a small grain (left) and a large grain (right). (b) EDX analysis reveals uniform Ti distribution in the small grain, but in the large grain $\mathrm{Ti}$ has higher concentration in the region near the grain boundary than in the region near the center. ter. This indicates that the elastic strain near the grain boundary facilitates the mixing of the Ti solute atoms into the $\mathrm{Mg}$ lattice. Figure $4 \mathrm{~b}$ also shows that the small grain has a higher concentration of $\mathrm{Ti}$, suggesting that the solubility of $\mathrm{Ti}$ increases with decreasing grain size. No intermetallic compound is observed in the EDX analysis, which is consistent with the X-ray analysis.

The segregation of $\mathrm{Ti}$ atoms to the region near the grain boundaries could have helped with the nucleation and growth of deformation twins observed in the nc hcp $\mathrm{Mg}-\mathrm{Ti}$ alloy. It is reported that dislocation nucleation and emission from the grain boundaries became a major deformation mode in nc fcc metals because of the lack of dislocation source in the grain interior [6,25-27]. The dislocation nucleation and emission likely also play a major role in nc hcp metals. Since the GPFE energies primarily affect the dislocation nucleation [28], the segregation of $\mathrm{Ti}$ atoms to the grain boundary region should strengthen the alloying effect on the dislocation nucleation, and might consequently help with the formation of deformation twins observed in the nc hcp Mg-Ti alloy.

The twinning system in the nc Mg-Ti alloy is $\{10 \overline{1} 1\}\langle 10 \overline{1} \overline{2}\rangle$, which can provide strain in the $c$-axis direction. In addition, a new slip system, $\{10 \overline{1} 1\}$ $\langle\overline{1} 123\rangle$, is also activated, which can also provide strain in the $c$-axis direction. In other words, both the deformation twinning and the newly activated slip system can facilitate plastic strain in the $c$-axis direction. This is significant for the nc hcp $\mathrm{Mg}$ - Ti alloy because it makes the total number of independent deformation systems larger than five, as required by the von Mises criterion for compatibility [29].

The activation of deformation twinning in the nc hcp $\mathrm{Mg}-\mathrm{Ti}$ alloy is most likely caused by the change in the GPFE curves caused by Ti alloying. This statement is supported by the following observations. First, nc hcp metals and alloys have rarely been observed to deform by twinning [12], although twinning is a major deformation mechanism in their coarse-grained counterparts. Ball-milled nanocrystalline $\mathrm{Mg}$ with grain sizes similar to our nc Mg-Ti alloy has been reported not to deform by twinning $[23,24]$. Second, twins were observed in all nc $\mathrm{Mg}$-Ti grains with an $\langle 11 \overline{2} 3\rangle$ zone axis, which indicates the prevalence of deformation twins in the $\mathrm{nc} \mathrm{Mg}_{-}$ Ti alloy. It should also be noted that the high strain rate used in the ball milling should also have promoted twinning in the nc Mg-Ti alloy [14]. This is because a higher strain rate usually leads to a higher flow stress.

Three important energies act on the GPFE curves: the stacking fault energy, the unstable stacking fault energy and the unstable twin fault energy [16]. These are energy barriers associated with the nucleation and gliding of partial and twinning dislocations. They have been reported to significantly affect the twinning tendency in fcc metals and alloys [16,30,31], and a similar effect should also apply to hcp metals such as Mg. For example, it is known that lowering the stacking fault energy promotes the deformation twinning in nc fcc metals and alloys [9-11,32-34]. Also, a lower unstable twin fault energy should make twinning easier. It would be of interest to calculate the GPFE curves of the hcp $\mathrm{Mg}-\mathrm{Ti}$ alloy as a function of $\mathrm{Ti}$ concentration in the future. 
In conclusion, deformation twinning has been activated in an nc hcp $\mathrm{Mg}-\mathrm{Ti}$ alloy, which is most likely caused by the modification of GPFEs through Ti alloying. The segregation of the $\mathrm{Ti}$ atoms near the grain boundaries makes the alloying effect stronger. These results suggest that it might be possible to design nc hcp $\mathrm{Mg}$ alloys to activate deformation twinning for improving the mechanical properties. In addition, new slip systems that are not available to their coarse-grained counterparts could be activated in nc hcp $\mathrm{Mg}$ alloys. Further studies are needed to investigate which elements are most effective in promoting deformation twinning in $\mathrm{nc} \mathrm{Mg}$ alloys. In addition, the physics of the grain size effect on deformation mechanisms of nc hep metals also needs further investigation.

X.L.W. acknowledges the support of NSFC Grant Nos. 11072243, 10721202, 973 Project Grant Nos. 2010CB631004 and 2007CB613700. Other coauthors were supported by the U.S. Army Research Office (W911NF-09-1-0427) and the Army Research Laboratory (W911QX-08-C-0083).

[1] Y.T. Zhu, X.Z. Liao, Nat. Mater. 3 (2004) 351.

[2] Y.M. Wang, M.W. Chen, F.H. Zhou, E. Ma, Nature 419 (2002) 912.

[3] Z. Horita, K. Ohashi, T. Fujita, K. Kaneko, T.G. Langdon, Adv. Mater. 17 (2005) 1599.

[4] K.M. Youssef, R.O. Scattergood, K.L. Murty, J.A. Horton, C.C. Koch, Appl. Phys. Lett. 87 (2005) 091904.

[5] K. Lu, L. Lu, S. Suresh, Science 324 (2009) 349.

[6] V. Yamakov, D. Wolf, S.R. Phillpot, A.K. Mukherjee, H. Gleiter, Nat. Mater. 1 (2002) 45.

[7] V. Yamakov, D. Wolf, S.R. Phillpot, H. Gleiter, Acta Mater. 50 (2002) 5005.

[8] Y.H. Zhao, J.E. Bingert, X.Z. Liao, B.Z. Cui, K. Han, A.V. Sergueeva, A.K. Mukherjee, R.Z. Valiev, T.G. Langdon, Y.T.T. Zhu, Adv. Mater. 18 (2006) 2949.

[9] Y.H. Zhao, X.Z. Liao, Z. Horita, T.G. Langdon, Y.T. Zhu, Mater. Sci. Eng. A 493 (2008) 123.

[10] Y.H. Zhao, X.Z. Liao, Y.T. Zhu, Z. Horita, T.G. Langdon, Mater. Sci. Eng. A 410 (2005) 188.
[11] Y.H. Zhao, Y.T. Zhu, X.Z. Liao, Z. Horita, T.G. Langdon, Appl. Phys. Lett. 89 (2006) 121906.

[12] Y.T. Zhu, X.Z. Liao, X.L. Wu, JOM 60 (2008) 60.

[13] M.A. Meyers, O. Vohringer, V.A. Lubarda, Acta Mater. 49 (2001) 4025.

[14] X.L. Wu, Y.T. Zhu, Phys. Rev. Lett. 101 (2008) 025503.

[15] L. Zhang, Y. Han, Mater. Sci. Eng. A 523 (2009) 130.

[16] H. Van Swygenhoven, P.M. Derlet, A.G. Froseth, Nat. Mater. 3 (2004) 399.

[17] K. Asano, H. Enoki, E. Akiba, J. Alloys Compd. 480 (2009) 558.

[18] G. Liang, R. Schulz, J. Mater. Sci. 38 (2003) 1179.

[19] B. Li, E. Ma, Acta Mater. 57 (2009) 1734.

[20] L. Capolungo, I.J. Beyerlein, Phys. Rev. B 78 (2008) 024117.

[21] I. Kim, J. Kim, D.H. Shin, X.Z. Laio, Y.T. Zhu, Scripta Mater. 48 (2003) 813.

[22] Y.B. Wang, M. Louie, Y. Cao, X.Z. Liao, H.J. Li, S.P. Ringer, Y.T. Zhu, Scripta Mater. 62 (2010) 214.

[23] H.J. Choi, Y. Kim, J.H. Shin, D.H. Bae, Mater. Sci. Eng. A 527 (2010) 1565.

[24] S. Hwang, C. Nishimura, P.G. McCormick, Scripta Mater. 44 (2001) 1507.

[25] Y.T. Zhu, X.Z. Liao, S.G. Srinivasan, E.J. Lavernia, J. Appl. Phys. 98 (2005) 034319.

[26] Y.T. Zhu, X.L. Wu, X.Z. Liao, J. Narayan, S.N. Mathaudhu, L.J. Kecskes, Appl. Phys. Lett. 95 (2009) 031909.

[27] Y.T. Zhu, J. Narayan, J.P. Hirth, S. Mahajan, X.L. Wu, X.Z. Liao, Acta Mater. 57 (2009) 3763.

[28] X.L. Wu, Y.T. Zhu, Appl. Phys. Lett. 89 (2006) 031922.

[29] W.F. Hosford, The Mechanics of Crystals and Textured Polycrystals, Oxford University Press, New York, 1993.

[30] S. Hai, E.B. Tadmor, Acta Mater. 51 (2003) 117.

[31] X.L. Wu, Y.T. Zhu, E. Ma, Appl. Phys. Lett. 88 (2006) 121905.

[32] Z.W. Wang, Y.B. Wang, X.Z. Liao, Y.H. Zhao, E.J. Lavernia, Y.T. Zhu, Z. Horita, T.G. Langdon, Scripta Mater. 60 (2009) 52.

[33] P.L. Sun, Y.H. Zhao, J.C. Cooley, M.E. Kassner, Z. Horita, T.G. Langdon, E.J. Lavernia, Y.T. Zhu, Mater. Sci. Eng. A 525 (2009) 83.

[34] L. Balogh, T. Ungar, Y. Zhao, Y.T. Zhu, Z. Horita, C. Xu, T.G. Langdon, Acta Mater. 56 (2008) 809. 